\title{
Efeito da aplicação de um dessensibilizante associado a quitosana no esmalte dental previamente ao clareamento.
}

\author{
Beatriz I. N. Lemos*; Laura N. Ferraz; Débora A. N. L. Lima.
}

\section{Resumo}

Esse estudo objetivou avaliar a aplicação prévia de agentes dessensibilizantes com quitosana sobre as propriedades físicas do esmalte dental clareado com peróxido de hidrogênio a $35 \%$. Espécimes de esmalte bovino $(4 \times 4 \mathrm{~mm})$ foram manchados em $100 \mathrm{ml}$ de chá preto durante 6 dias e em seguida foram aleatorizados em 5 grupos $(n=12)$ de acordo com o dessensibilizante utilizado: G1: sem aplicação de dessensibilizante; G2: aplicação de fluoreto de sódio neutro a 2\%; G3: aplicação de fluoreto de sódio neutro a $2 \%$ com quitosana a $2 \%$; G4: aplicação de fluoreto de sódio a $2 \%$ e nitrato de potássio a $5 \%$; G5: aplicação de fluoreto de sódio a $2 \%$ e nitrato de potássio a $5 \%$ com quitosana a $2 \%$. Todos os grupos foram clareados com peróxido de hidrogênio a 35\%. Foram realizadas 3 sessões de clareamento com intervalo de 7 dias entre elas. Em cada sessão foi realizado 3 aplicações de gel pelo tempo de 15 minutos. Previamente ao clareamento, o dessensibilizante foi aplicado pelo tempo de 10 minutos. A análise de cor foi realizada após o manchamento com chá preto e após cada sessões de clareamento. A microdureza de superfície do esmalte foi analisada após a última sessão de clareamento. Os dados de microdureza foram submetidos à ANOVA e teste de Tukey. Para os dados de cor, foi realizado a análise de medidas repetidas com PROC MIXED e teste de Tukey-Kramer. Para a microdureza, o grupo sem aplicação prévia de dessensibilizante apresentou os menores valores diferindo estatisticamente dos outros grupos e o o grupo G3 apresentou os maiores valores de microdureza de superfície entre os dessensibilizantes avaliados. Para a análise de cor, não foram encontradas diferenças estatísticas significantes entre os grupos. A aplicação de agentes dessensibilizantes a base de fluoreto de sódio neutro a $2 \%$ ou fluoreto de sódio neutro a $2 \%$ e nitrato de potássio a $5 \%$, associados ou não a quitosana a $2 \%$, são capazes de previr a diminuição da microdureza do esmalte dental, melhorando assim as suas propriedades físicas após o clareamento com peróxido de hidrogênio a 35\% sem que haja interferência na eficácia clareadora.

\section{Palavras-chave:}

Quitosana, dessensibilizante, peróxido de hidrogênio..

\section{Introdução}

O clareamento dental é considerado seguro, eficaz, de fácil execução e fornece resultados estéticos satisfatórios ${ }^{1}$, porém um dos principais efeitos adversos dos agentes clareadores é a sensibilidade dentinária ${ }^{2}$. Devido a isso, uma das recomendações para reduzir a sensibilidade dental causada pelo clareamento, é a utilização de agentes dessensibilizantes e remineralizantes ${ }^{3}$ como o flúor e 0 nitrato de potássio sem reduzir a eficácia clareadora.

Com o objetivo de diminuir a desmineralização do esmalte dental e melhorar ainda mais as propriedades físicas após o clareamento dental, é interessante a associação de novos compostos aos agentes dessensibilizantes para potencialização desse efeito protetor. Uma abordagem ainda não avaliada é a adição de polissacarídeos, como a quitosana ao agente dessensibilizante. A quitosana forma multicamadas ${ }^{4}$ que são estáveis em pH ácido e notavelmente mais resistentes a condições cíclicas de $\mathrm{pH}$, evitando o processo de desmineralização.

Assim, o presente estudo tem como objetivo avaliar a aplicação prévia de um agente dessensibilizante associado aquitosana sobre as propriedades físicas do esmalte dental clareado com peróxido de hidrogênio a $35 \%$.

\section{Resultados e Discussão}

Para a análise de microdureza de superfície, o grupo sem aplicação prévia de dessensibilizante apresentou os menores valores diferindo estatisticamente dos outros grupos. Em relação aos dessensibilizantes, os grupos G2, G4 e G5 apresentaram valores intermediários e não diferiram estatisticamente entre si. Já o grupo G3 apresentou os maiores valores de microdureza de superfície sendo estatisticamente diferente de todos os outros grupos avaliados. Para a análise de cor, não foram encontradas diferenças estatísticas significantes entre os grupos para $\Delta \mathrm{L}, \Delta \mathrm{a}, \Delta \mathrm{b}$ e $\Delta \mathrm{E}$.

\section{Conclusões}

A aplicação de agentes dessensibilizantes a base de fluoreto de sódio neutro a $2 \%$ ou fluoreto de sódio neutro a $2 \%$ e nitrato de potássio a $5 \%$, associados ou não a quitosana a $2 \%$, são capazes de previr a diminuição da microdureza do esmalte dental, melhorando assim as suas propriedades físicas após o clareamento com peróxido de hidrogênio a 35\% sem que haja interferência na eficácia clareadora.

\section{Agradecimentos}

Ao PIBIC pela bolsa concedida.

${ }^{1}$ Basting R, Amaral F, Francça F, Florio F. Clinical comparative study of the effectiveness of and tooth sensitivity to $10 \%$ and $20 \%$ carbamide peroxide homeuse and $35 \%$ and $38 \%$ hydrogen peroxide in-office bleaching materials containing desensitizing agents. Oper Dent 2012; 37: 464-73.

${ }^{2}$ Pashley DH. Dentin permeability, dentin sensitivity, and treatment through tubule occlusion. JEndod1986; 12:465-74.

3JorgensenMG,CarrollWB(2002) Incidence of tooth sensitivity after home whitening treatment. J Am Dent Assoc 133:1076-1082.

${ }^{4}$ Guo C, Gemeinhart RA. Understanding the adsorption mechanism of chitosan onto poly (lactide-co-glycolide) particles. Eur J Pharm Biopharm. 2008 Oct;70(2):579-604. 